\section{Finney-Howell Research Foundation}

AT the death of the late Dr. George Walker of Baltimore his will provided for the formation of a corporation to be known as the Finney-Howell Research Foundation, the purpose of which was to be the support of "research work into the cause or causes and the treatment of cancer". The will directed that the surplus income from the assets of the Foundation together with the principal sum should be expended within a period of ten years to support a number of fellowships in cancer research, each with an annual stipend of two thousand dollars, "in such universities, laboratories or other institutions, wherever situated, as may be approved by the Board of Directors". Fellowships will be awarded each year on the second Wednesday of March, beginning March 1938. These fellowships will be awarded for a period of one year with the possibility of renewal up to three years. Further information can be obtained from the secretary of the Foundation, Dr. William A. Fisher, Medical and Chirurgical Faculty Building, 1211 Cathedral Street, Baltimore, Maryland.

\section{Meteors}

ON November 9, about $21^{\text {h }} 25^{\mathrm{m}}$ G.M.T., Mr. J. E. Daly, in North London, saw a meteor of magnitude equal to that of Jupiter, moving from the direction of the planet Saturn towards the west. Its motion was nearly parallel to the ecliptic, and its path was over $30^{\circ}$. No other observations of this meteor were reported, so it is impossible to give any details of its real path. On November 20 , at $8^{\mathrm{h}} 23^{\mathrm{m}}, \mathrm{a}$ bright fireball was seen by two observers in Rathmines and Mullingar, travelling from south-east to north-west. The body of the fireball gave out an intense bluishwhite light, and it had a trail two to three times the apparent diameter of the moon. As it was quite light at the time, it was impossible to describe its path with sufficient precision to enable its height, etc., to be computed. If it had been dark at the time, it is certain that the fireball would have been a very imposing sight.

\section{World Power Conference: Vienna Sectional Meeting}

A sectional meeting of the World Power Conference will be held in Vienna next year on August 25September 2, by invitation of the Austrian National Committee. The meeting will be followed by one or more 'study tours' of approximately a week's duration. We understand that the British Government has received an invitation to be represented by official delegates at Vienna. The British National Committee, 36 Kingsway, London, W.C.2, has copies in English of the technical programme of the Vienna Sectional Meeting. It is divided into five sections, dealing with the supply of energy for agriculture, small-scale industries, household purposes, public lighting and electric railways. The term 'small-scale industries' is used to cover both handicrafts and industries employing a relatively small number of workmen, about twenty or thirty; in addition, hotels, cafés, restaurants and shops. The kinds of motive power used should be mentioned : solid and liquid fuel, gas, water power, wind power, steam or electricity, and stress should be laid on those of special importance. Information should be included on the use of human and animal as compared with mechanical power, and the influence of the latter on civilization and health. Technical and economic comparisons between the supply of energy from public electric or gas mains and from private plant would be welcome. Data about lighting power and heat in small-scale industries with special reference to the tools and the drive of the appliances employed, and in particular, room heating, air conditioning, cooking (on a large scale) in restaurants, bakers' ovens and welding. Under the section for the supply of energy for public lighting is included the energy used in traffic lighting, as on railways, for shipping, in air transport, and in traffic control signals.

\section{Announcements}

Mr. E. Harrison, director of agriculture for Tanganyika, has been appointed professor of agriculture at the Imperial College of Tropical Agriculture, Trinidad.

Dr. Julian Huxley will deliver the Christmas Lectures (a course of six lectures adapted to a juvenile auditory) of the Royal Institution on December 28, 30, January 1, 4, 6 and 8 . The subject of the lectures will be "Rare Animals and the Disappearance of Wild Life". Further information can be obtained from the Secretary, Royal Institution, 21 Albemarle Street, London, W.1.

ON the occasion of the eightieth birthday of Bernhard Nocht, founder of the Institute of Tropical Medicine at Hamburg, the Bermhard Nocht Medal has been awarded to the following, in recognition of their services to tropical medicine: Prof. J. Rodhain (Belgium), Prof. E. Brumpt and Dr. W. Fourneau (France), Profs. E. Martini and E. Reichenow (Germany), Dr. P. Manson-Bahr and Prof. G. H. F. Nuttall (Great Britain), Profs. E. P. Snijders and N. H. Swellengrebel (Holland), Prof. G. Bastianelli and Sir Aldo Castellani (Italy).

Messrs. E. P. Goldschmidt ANd Co., Ltd., of 45 Old Bond Street, W.1, in their latest catalogue, No. 45, offer a selection of important books in the history of science, and also a few early microscopes. Noteworthy items are the astronomical classics, Copernicus' "De Revolutionibus Orbium" (1543), and Kepler's "Astronomia Nova" (1609). They also catalogue that bibliographical rarity, the original edition (1669) of Nicholas Steno's "De Solido intra Solidum", described by Sir Archibald Geikie as "one of the landmarks in the history of geological investigation". The interest of the catalogue is enhanced by many informative notes, and also by reproductions of title. pages and illustrations. 